\title{
Psicogênese da língua escrita: gênese e estrutura de um marco na história da alfabetização no Brasil
}

\begin{abstract}
Resumo: O nosso objetivo é problematizar historicamente o lugar ocupado pelo livro Psicogênese da língua escrita, de Emilia Ferreiro e Ana Teberosky, no cenário nacional dos discursos referentes à aquisição da língua escrita e às práticas escolares de alfabetização. Para tanto, de acordo com a tradição da pesquisa em Epistemologia Genética, fazemos uso dos eixos diacrônico e sincrônico da História do Pensamento Educacional Brasileiro. Diacronicamente, nós identificamos a trajetória de três sujeitos ordenadores do discurso sobre alfabetização: o sujeito da Pedagogia Científica, situado na passagem do século XIX para o século XX; o sujeito da Psicometria, situado entre os anos 1920 e 1950; e o sujeito da Psicolinguística, nascido na passagem dos anos 1950 para os anos 1960. Sincronicamente, caracterizamos a guerra dos métodos (Construtivismo x Método Fônico) como uma operação de décalage vertical em nossa historiografia. Concluímos, enfim, que, entre assimilações deformantes e equilibrações majorantes, é impossível não reconhecer o lugar de destaque ocupado por Ferreiro e Teberosky na ordem do discurso sobre alfabetização em nosso país.
\end{abstract}

Palavras chaves: Psicogênese da escrita. Língua escrita. Alfabetização. Historiografia.

Introdução

Publicado no Brasil, em sua primeira edição no ano de 1985, o livro Psicogênese da língua escrita de Emília Ferreiro e Ana Teberosky pode ser considerado um marco na história da alfabetização em nosso país. Nosso objetivo, neste trabalho, é realizar um exercício historiográfico do lugar por ele ocupado no cenário nacional dos discursos referentes à aquisição da língua escrita e às práticas escolares de alfabetização tendo a Epistemologia Genética como eixo norteador da nossa metodologia de pesquisa.

De acordo com a tradição da pesquisa em Epistemologia Genética, aqui fazemos uso dos eixos diacrônico e sincrônico da História do Pensamento Educacional Brasileiro para fins da análise destes discursos. Diacronicamente, nós adaptamos a seminal periodização proposta por Maria do Rosário Longo Mortatti (2000) para história da alfabetização no Brasil, a saber: a metodização do ensino de leitura; a institucionalização do método analítico; alfabetização sob medida; e alfabetização: construtivismo e desmetodização. Sincronicamente, nossa atenção se centra no que conhecemos na literatura nacional sobre alfabetização como guerra dos métodos:
Paulo Gurgel Universidade Federal da Bahia pgpaulogurgel@gmail.com 
(1) O conceito de décalage não é de fácil apreensão na obra de Jean Piaget e dos seus colaboradores. Aqui ele é usado no sentido de retrocesso, ou seja, um retorno à uma etapa anterior do desenvolvimento do pensamento no campo da história das ciências (2) Aqui a expressão Ordem do Discurso nomeia o conjunto de procedimentos internos e externos de inclusão e exclusão de conteúdos e formas de enunciados de um discurso produzido em um determinado campo do saber que, em nosso caso, é o campo do saber sobre Alfabetização. Cf Foucault (1998).
Construtivismo x Método Fônico. Enfim, tecemos nossas considerações finais concluindo que, entre assimilações deformantes e equilibrações majorantes, é impossível não reconhecer o lugar de destaque ocupado pelo livro Psicogênese da língua escrita no cenário da alfabetização do Brasil. Procedemos, então, a uma chamada ao engajamento de pesquisadores do campo em duas tarefas distintas. A primeira delas é a superação do atual estado de décalage ${ }^{1}$ em que se encontra a discussão sobre métodos de alfabetização. A segunda delas é o nosso compromisso ético com a profissionalização de docentes alfabetizadores nesta aurora do século XXI.

\section{Psicogenése da língua escrita: uma pespectiva diacrônica}

Recordemos a história da alfabetização no Brasil com a colaboração de Maria do Rosário Longo Mortatti (2000) em sua pesquisa sobre o tema, ainda que circunscrita ao estado de São Paulo do ano de 1879 a 1990. Adaptando a periodização proposta pela autora aos nossos fins neste artigo, interrogamo-nos: oferecerá nossa periodização indícios da confirmação da hipótese da Epistemologia Genética sobre a lógica evolutiva do pensamento da ciência? Seria o pensamento de Ferreiro e Teberosky logicamente mais operatório do que o pensamento dos seus antecessores nesta linha do tempo? Se for, então devemos confirmar a hipótese da Epistemologia Genética sobre evolução do pensamento científico: as teorias se sucedem segundo uma ordem de complexidade lógica ao longo da história do pensamento. Eis a complexa questão que nos ocupa neste instante.

O primeiro período desta história se inicia em 1876, data da primeira edição da Cartilha maternal ou arte da leitura, escrita pelo poeta português João de Deus, e se estende até o ano de 1934, data da primeira edição do livro Testes $A B C$, de Manuel Bergström Lourenço Filho. Neste primeiro momento, a Ordem do Discurso ${ }^{2}$ sobre alfabetização tem como núcleo gerador a disputa entre os partidários dos métodos analíticos (palavração, sentenciação e historietas) e dos métodos sintéticos (soletração e silabação), nos quais se baseavam as primeiras cartilhas produzidas no Brasil. Reproduzimos, a seguir, um eloquente extrato deste confronto:

O processo de leitura, na sua evolução histórica, passou pelos três estados da lei. Foi theologico na soletração, 
tornou-se metafísico na sylabação, e é finalmente positivo ou scientífico na palavração. Esta ultima phase foi inaugurada pela cartilha maternal. [...] Na palavração, os elementos de toda a organização thechnica do processo de leitura são as proprias palavras, como sendo e constituindo a realidade, e é pelo methodo geral de analyse recaindo sobre as palavras que o espírito determina por um lado os últimos resíduos da palavra quando ella se decompõe, as lettras com os seus exatos valores, por outro as leis legítimas e simples que devem presidir à organização da palavra. Assim a idéia sobe das coisas para o espírito, como sucede na concepção positivista. (CANDIDO, 1883 apud MORTATTI, 2000, p. 60-61)

Estamos diante de uma defesa cientificamente justificativa em uma perspectiva evolucionista. Forte, então, batia o coração positivista da Pedagogia Científica em sua cruzada contra o obscurantismo intuitivo da tradição pedagógica do ensino das primeiras letras. Tempos de fé na ordem e progresso. E para que melhor possamos avaliar o grau de importância desta disputa em torno dos métodos de alfabetização no campo da pedagogia, aqui registramos o significativo ato de institucionalização do método analítico por Oscar Thompson, em sua primeira gestão da Diretoria Geral da Instrução Pública do Estado de São Paulo, nos anos de 1909 e 1910. Somente dez anos depois, com a Reforma Sampaio Dória (Lei $n^{0} 1.750$ de 1920), aos professores paulistas foi novamente concedida autonomia didática para escolha entre método sintético e método analítico.

Estamos, não na sombra da dúvida, mas sem a sombra desta, dentro do caro binômio SABER-PODER que nos foi legado por Foucault (1986) em seus estudos genealógicos. Há, em se tratando da história da alfabetização em nosso país, uma clara convergência do projeto político republicano de construção de uma nação brasileira e a efervescência de uma produção discursiva gerada na Escola Normal da Praça na cidade de São Paulo e em seus anexos. Assim, propomos que o núcleo gerador desta saudável querela dos métodos tenha sido o projeto de uma Pedagogia Científica, que tinha na figura do professor o seu sujeito. Era em torno dos métodos utilizados pelo professor que, então, se produzia saberes sobre o ideal de práticas pedagógicas cientificamente referenciadas.

O segundo momento da história da alfabetização no Brasil, A alfabetização sob medida, aponta para a entrada em cena do su- 
jeito da Psicometria através da publicação da primeira edição de Testes $A B C$ para verificação à maturidade necessária ao aprendizado da leitura e da escrita, em 1934. Lourenço Filho apresenta, neste livro, o resultado de pesquisas realizadas com alunos do primeiro ano do Ensino Fundamental a fim de buscar soluções para as dificuldades enfrentadas pelas crianças no aprendizado da leitura e da escrita. Para tanto, necessário se fazia segundo ele, enquanto primeiro passo, sublinhar a esterilidade do debate entre defensores do método sintético e do método analítico:

Neste debate de processos, a criança tem ficado esquecida. Falamos da criança real, da criança viva, com as suas mil diversidades individuais. As escolas não as têm considerado, diz Claparède. Não são dignas de solicitude da escola senão as crianças que se conformam com certo tipo esquemático que a escola criou à sua imagem, ou seja, um tipo monstruoso e contrário à natureza: o do aluno médio. (LOURENCO FILHO, 1967, p. 17)

Deslocando o eixo ordenador do discurso sobre alfabetização no Brasil da Pedagogia Científica e dos seus métodos de ensino para a figura do aluno, Lourenço Filho (1967, p. 17) inaugura uma nova ordem discursiva que tinha como eixo gerador o sujeito da Psicometria:

Pode-se ensinar a ler, e a ler bem, metodicamente, levando a criança, à finalidade exata e perfeita do aprendizado, sem prejuízo algum de seu desenvolvimento, por mil e um modos. A própria silabação pode ser empregada como ponto de partida, com tais artifícios de motivação, que dê esse resultado. Mas não há artifício mágico que ensine a ler, nem cremos que possa ser inventado. Há artistas que o fazem com maiores ou menores recursos de aplicação científica ou de intuição natural, isso sim.

Fica claro, portanto, que, a partir do ponto de vista do criador dos testes do ABC, a importância dos métodos e seus calorosos debates, que constituíram o primeiro tempo desta nossa história, já não mais poderiam se justificar.

Subordinando a aprendizagem da leitura e da escrita a uma métrica dos níveis de maturidade psicológica do aluno, este período foi, então, marcado pelo uso de cartilhas de alfabetização que se baseavam predominantemente em métodos mistos ou 
ecléticos (analítico-sintético e vice-versa). O sucesso da empresa de alfabetização não mais era função exclusiva do ato pedagógico capitaneado pelo professor, objeto da Pedagogia Científica, mas do grau de prontidão regente da configuração das classes seriadas por níveis de maturidade psicomotora e audiovisual dos seus alunos:

Os testes $\mathrm{ABC}$ indicam a probabilidade de as crianças aprenderem a ler, mais ou menos rapidamente. Convém, assim, separá-las em grupos ou classes tão homogêneas como possível. Os mestres conhecedores de sua arte sabem das vantagens de tratar um grupo homogêneo, ao invés de tratar com um grupo de crianças de diferentes aptidões para o trabalho escolar. (LOURENCO FILHO, 1969, p. 96)

Por que, então, não se perpetuou como sucesso o proposto por Lourenço Filho? Afinal, suas teses foram estatisticamente comprovadas segundo análise exaustiva de dados no capítulo segundo de seu livro Testes ABC. O deslocamento epistêmico da Pedagogia Científica para o campo da Psicometria, contudo, não cumpriu a promessa de sua boa nova. Muitas parecem ser as razões para tanto, e ainda que não seja objetivo deste nosso trabalho elencá-las, desejamos aqui sublinhar uma delas: a emergência da psicolinguística como novo ordenador do discurso da aquisição da língua escrita.

A primeira edição do livro Psicogênese da língua escrita, de Emilia Ferreiro e Ana Teberosky no ano de 1985, inicia o mais atual período da história da alfabetização no Brasil. Deslocando o eixo da discussão da criança real em desenvolvimento diferencial, tal como encontrada na tradição psicométrica, para o sujeito cognoscente universal em processo de construção do seu conhecimento sobre a língua escrita, as autoras introduzem, no debate sobre alfabetização no Brasil, o sujeito da Psicolinguística:

Não somos nós os primeiros a assinalar a necessidade de proceder uma revisão completa de nossas idéias sobre a aprendizagem da língua escrita, a partir das descobertas da psicolingüística contemporânea. Em 1971 tem lugar nos Estados Unidos uma conferência sobre a 'relação entre a fala e a aprendizagem da leitura', que se constitui no primeiro intento global nesse sentido. (KAVANAGH; MATTINGLY, 1972)

Desde então, autores como Kenneth Goodman, Frank Smith, Charles Read e Carol Chomsky produziram vá-

revista entreideias, Salvador, n. 01, p. 119-130, jan./jun. 2012123 
rios trabalhos importantes sobre esse problema. Nossa originalidade reside em sermos, provavelmente, os primeiros a fazê-lo em língua espanhola e, principalmente, os primeiros a vincular essa perspectiva com o desenvolvimento cognitivo, tal como é visto na teoria da inteligência de Piaget. (FERREIRO; TEBEROSKY, 1985, p. 25)

Optamos por reproduzir estes dois parágrafos da obra para deixar muito claro ao leitor de que lugar elas se fazem ouvir, ou melhor, de que lugar elas enunciam suas teses. Ainda que vinculadas à Teoria da Inteligência de Jean Piaget, é da ordem do discurso da Psicolinguística que Ferreiro e Teberosky assinalam a necessidade de procedermos a uma revisão completa de nossas ideias sobre a aprendizagem da língua escrita.

O livro Psicogênese da língua escrita é um denso e longo relatório de uma pesquisa experimental realizada com crianças em Buenos Aires nos anos de 1974, 1975 e 1976. Partindo do princípio que "o ato de compreender a natureza do sistema da escriata e sua função suscita problemas fundamentais, ao lado dos quais a discriminação das formas, seu traçado, a capacidade de acompanhar um texto com os olhos etc., tornam-se completamente secundários" (FERREIRO; TEBEROSKY, 1985, p. 13), suas autoras, ao longo de oito capítulos, incluindo Introdução e Conclusões, apresentam de maneira translúcida a riqueza que encontraram nas etapas percorridas pela criança em sua aventura epistêmica de apropriação do sistema da escrita alfabética. Mais tarde, com os desdobramentos da obra, mais precisamente no universo das práticas de alfabetização, toda esta aventura nos aparece na literatura em versão simplificada de fases da aprendizagem do sistema da escrita, a saber: pré-silábica, silábica, silábica-alfabética e alfabética.

Mortatti (2000) assinala que a entrada de Emília Ferreiro no cenário da história da alfabetização no Brasil provocou uma verdadeira revolução conceitual. Em seu primeiro movimento, esta revolução, assim pode nos parecer, resultou no confronto com métodos até então utilizados, o que se traduziu em uma verdadeira caça às cartilhas, tal como se caçaram bruxas em tempos do Santo Ofício. Esta é uma leitura possível, ainda que não necessária. A centralidade dos métodos neste debate da alfabetização em nosso país já houvera sido superada pelo movimento de psicometrização do sujeito da alfabetização, operado por Lourenço Filho. 
A dita revolução conceitual causada pelo livro, e que não cessa de surpreender até hoje, é a simples constatação de que o sujeito da aquisição da lectoescrita não se reduz ao sujeito-aluno como propôs o nosso doutor do $A B C$, Lourenço Filho. Dito de outra forma: quando a criança se torna aluna, muito ela já pode ter aprendido sobre o universo das cartilhas que lhe apresentam suas professoras. Portanto, há de se levar em conta os percursos trilhados pelas crianças em contato com o mundo das letras e do que deste contato é resultante. Mesmo sem as medidas necessárias, e desde muito cedo, aprendemos a ler o mundo e a nele deixarmos nossas marcas escritas.

Visto isto, retomemos aqui o nosso problema epistemológico em sua dimensão diacrônica: enquanto a obra, Psicogênese da língua escrita é prima? Ou melhor: Ferreiro e Teberosky inaguram um nível mais elaborado de se pensar os problemas de Aquisição da Língua Escrita na História da Alfabetização no Brasil? Sim, esta é a nossa resposta. E, então, por que tanta polêmica, ainda hoje, mais de 25 anos depois?

\section{Psicogênese da língua escrita: uma perspectiva sincrônica}

O estado atual da arte da pesquisa em alfabetização no Brasil parece, em uma primeira aproximação ao tema, concentrar-se naquilo que, pelo menos como veiculado na mídia, ficou conhecido pelo nome de querela dos métodos: Construtivismo x Método Fônico. E aqui vale destacar o duelo travado por Telma Weiss e Fernando Capovilla em matérias veiculadas pelo jornal Folha de S. Paulo no ano de 2006. Façamos, contudo, uma démarche epistemológica para por em xeque a natureza mesma desta querela em nosso tempo.

Vimos que os Testes do $A B C$, que tinham como instrumento uma métrica da prontidão, transladaram do campo da Pedagogia Científica para o campo da Psicometria o núcleo do objeto da aprendizagem da leitura e da escrita. Métodos, desde então, passaram à condição de acessórios, ainda que as cartilhas fossem seus instrumentos essenciais da materialização das práticas de professores nas salas de aula. Vimos, então, que Ferreiro e Terebosky operaram um novo deslocamento neste mesmo núcleo do objeto da aprendizagem da língua escrita ao proporem ser, não o sujeito da Psicometria, mas o sujeito da Psicolinguística, o objeto 
a ser investigado por excelência. E, para tanto, fizeram uso dos avanços da gramática gerativa de Noam Chomsky e das teses de Jean Piaget sobre o desenvolvimento da inteligência na criança. Portanto, hoje, mais de 75 anos depois do fim da Era dos Metodistas Sintéticos e dos Metodistas Analíticos e mais de 25 anos do fim da era dos Metodistas Mistos, não cremos ser epistemologicamente correto nos referirmos ao Construtivismo e Consciência Fonológica como métodos.

Os tempos são outros, ainda que a lei da inércia também se aplique ao pensamento pedagógico. Os últimos cinquenta anos do século XX trouxeram à cena da Epistemologia da Língua Escrita novos olhares tanto para o sujeito como para o objeto da alfabetização. Preciosas hipóteses foram geradas e novos campos foram constituídos: muito além da Pedagogia Científica e da Psicometria, surgiram um grande número de estudos no campo da Linguística, da Psicolinguística e da Sociolinguística. Assim, tanto o sujeito como o objeto da alfabetização se fragmentaram em uma exponencial velocidade de produção de novos saberes sobre como aprendemos a ler a escrever.

A Gramática Gerativa de Noam Chomsky, em conjunção com o estruturalismo linguístico de Ferdinand de Saussure, puseram em xeque a simplicidade do modelo da linguística estrutural de Bloomfield e de suas hipóteses associacionistas sobre a arquitetura e sobre a aquisição das línguas humanas. Estudos em fonologia e sintaxe, principalmente, resultaram em mais um golpe em nosso imaginário narcísico: já não nos bastasse a certeza da terra não ser o centro do universo, do homem não ter sido criado à imagem e semelhança de Deus e do cogito não ser o centro único da razão, ainda tivemos que sobreviver à certeza de que não dominamos uma língua, e sim somos subordinados à sua gramática.

Resultante da convergência dos estudos linguísticos com estudos em psicologia cognitiva, o campo da psicolinguística, mais especificamente aquele dedicado à pesquisa dos processos de aquisição da língua escrita, aflorou, dividido em duas vertentes concorrentes. Em se tomando o ensino e aprendizagem da leitura como referência, encontramos na literatura anglo-saxônica dois termos bem distintos para estas duas vertentes: modelo top-down e modelo button-up de processamento de dados. ${ }^{3}$ Duas formas antagônicas do sujeito do conhecimento se relacionar com as letras e que vão estar na base da discussão sobre aquilo que, pelo menos 
para nós, é incorreto denominar como querela dos métodos em nosso tempo.

Resultante da convergência dos estudos linguísticos com estudos das Ciências Sociais, o campo da Sociolinguística enuncia, desde o seu nascimento nos anos sessenta, que a performance linguística de um falante das classes populares não é resultante de uma deficiência ou de um erro de aquisição. A variação linguística não é corruptela, mas uma das muitas formas de materialização da competência dos falantes de uma língua. Os falares da gente trazem consigo a marca das nossas origens sócio-históricas. Não é, portanto, de admirar que ao mundo da alfabetização e do ensino das línguas maternas tenham sido acopladas referências recorrentes aos psicólogos e aos linguistas da extinta União Soviética de onde herdamos um inestimável legado de trabalhos que tomaram o Materialismo Dialético como referencial teórico.

Ainda que compactado, este nosso sincrônico voo epistemológico nos autoriza a afirmar a atual natureza transdisciplinar do campo da alfabetização. Expressivas são as contribuições advindas do trabalho de linguistas, psicolinguistas e sociolinguistas. Portanto, reduzir este debate a uma guerra de métodos é minimamente desconhecer preciosas contribuições de cada um destes trabalhos e reduzir todo o esforço de tantos pesquisadores a uma operação de assimilação deformante, historicamente derivada da tradição metodista herdada da Pedagogia Científica dos primórdios do século XX.

Por que, então, a literatura extemporaneamente ainda insiste em fazer referência a uma guerra de métodos para nomear dois modelos concorrentes no campo da pesquisa em Psicolinguística que, em nossa literatura, é sempre referido como a querela entre defensores do Método Fônico e Construtivismo? Aqui supomos se tratar da mais deformante de todas as assimilações deformantes que permeiam este anacronismo semântico na história da alfabetização no Brasil. Ora, já há muito se insiste que o construtivismo não é método, mas abordagem. Hora também de chamarmos atenção para a natureza perversa do sintagma Método Fônico, que injustamente reduz ao universo das cartilhas o belo trabalho de pesquisa realizado nos últimos anos referentes ao campo dos estudos sobre Metalinguagem e Aquisição da Língua Escrita, a saber: consciência fonológica, consciência morfológica, consciência sintática e consciência lexical. ${ }^{4}$
(3) O modelo button-up propõe ser o ato de ler simples decodificação, ou seja, o processamento de grafemas em fonemas em

operações cognitivas traduzidas em rotas lexicais e fonológicas. O modelo top-down propõe ser $o$ ato de ler uma operação de decifração do texto em que muitos são os fatores cognitivos envolvidos, com destaque para a dimensão sócio-histórica do leitor (4) Recomendo ao leitor a leitura extensiva do excelente livro organizado por Maria Regina Maluf (2003) para uma apreciação detalhada das contribuições das pesquisas em habilidades metalinguísticas no campo da aquisição da língua escrita e suas implicações para práticas de alfabetização. 
Supomos já poder contar com um número suficiente de novas estruturas epistêmicas para que possamos antever equilibrações majorantes no horizonte próximo do campo da alfabetização. Certamente as estruturas construídas por Ferreiro e Teberosky tiveram e têm lugar capital neste processo evolutivo. Não há como negar que o livro Psicogênese da língua escrita publicado pela primeira vez no Brasil há vinte e cinco anos desempenhou um papel fundamental na desequilibração das estruturas cognitivas do pensamento educacional brasileiro, sobremaneira ao que se refere à alfabetização. E a esta desequilibração, Mortatti denominou de desmetodização.

Tenhamos, contudo, muito cuidado com o uso da palavra desmetodização. Resultante do processo de institucionalização das ideias centrais do livro Psicogênese da língua escrita no Brasil, ela não necessariamente, deve nos remeter a uma elegia da panaceia pedagógica das práticas de alfabetização. Errado é considerar que aquilo que encontramos atualmente na literatura sob a etiqueta de construtivismo signifique, necessariamente, uma décalage vertical à Pedagogia Froebelina dos Jardins de Infância, regada pelo espontaneísmo desenvolvimentista de jardineiras.

\section{Considerações finais}

É chegado o instante de tecermos considerações finais sobre esta nossa aventura epistêmica, que é uma homenagem aos vinte cinco anos da primeira edição do livro Psicogênese da língua escrita em nosso país. Em um exercício dialético de síntese, tentaremos, em uma operação, compactar dois eixos coordenados deste nosso exercício epistemológico: a psicogênese da língua escrita em sua dimensão diacrônica e a psicogênese da língua escrita sua em dimensão sincrônica.

Recorremos à dimensão diacrônica da alfabetização no Brasil para propor a eleição do livro de Ferreiro e Teberosky como marco referencial de um novo paradigma de abordagem da aquisição da língua escrita em nosso país: o paradigma Psicolinguístico. É com as teses sobre estágios da construção de hipóteses sobre estrutura e funcionamento do mundo da escrita pela criança que as autoras introduzem o sujeito da Psicolinguística em nosso universo da alfabetização em substituição ao sujeito da psicometria, introduzido por Lourenço Filho, por ocasião da publicação da primeira edição do livro Testes do $A B C$, em 1934. 
Sincronicamente, identificamos na querela dos métodos, construtivista e fônico, um efeito de décalage vertical que reeditou, ao final do século passado, a guerra dos métodos analíticos e sintéticos, marca da História da Alfabetização no Brasil no alvorecer do século XX. Para tanto, demonstramos que a atual configuração acadêmica da pesquisa no campo da aquisição da língua escrita no mundo não mais tem como referentes o paradigma da Pedagogia Científica geradora da antítese: Métodos Sintéticos e Métodos Analíticos e o paradigma da Psicometria, geradora das classes homogêneas de alfabetização. Operamos, hoje, com uma perspectiva transdisciplinar na qual se destaca, sobremaneira, as contribuições de Ferreiro e Teberosky para superação do aprisionamento da prática docente ao suave mundo das cartilhas.

Propomos, enfim, duas tarefas de grande porte a realizarmos: uma de cunho teórico e a outra de natureza prática; ambas, contudo, tendo a promoção de equilibrações majorantes como fim. A primeira delas é a superação do atual estado de décalage vertical em que se encontra a discussão sobre métodos de alfabetização. A segunda delas é o nosso compromisso ético com a profissionalização de docentes alfabetizadores nesta aurora do século XXI. É chegado o tempo da academia, mais especificamente, o tempo das Faculdades de Educação do Brasil, intensificarem sua inserção nas Redes Públicas de Ensino com o objetivo de promover condições necessárias à transcendência de discursos e práticas de alfabetização para além do lugar comum das assimilações deformantes geradoras de distorcidas representações e práticas do ensino da leitura e da escrita a partir de uma obtusa, e suposta, guerra de métodos. Dois grandes desafios epistêmicos à vista.

\title{
Psychogenesis of the written language: genesis and structure of a turning point in the history of literacy in
}

Brazil

\begin{abstract}
Our aim is to historically problematize the place occupied by the book Psychogenesis of the written language, by Emilia Ferreiro \& Ana Tereberosky, in the national scenario of the discourses related to written language acquisition and to literacy school practices. For doing so, in accordance to the research tradition in Genetics Epistemology, we make use of the diachronic and synchronic axes of the Brazilian Educacational Thought History. Diachronically, we identified three subjects ordering the discourse on literacy: the subject of Scientific Pedagogy, situated on the turn of the XIX to to the
\end{abstract}


XX Century; the the subject of Psychometrics, situated between the 20ths e and the 50ths; and the subject of Psycholinguistics, born on the turn of the 50 ths to the 60ths. Synchronically, we characterize the war in methods (Constructivism $\mathrm{x}$ Phonics) as an operation of vertical décalage in our history. We conclude, then, among deforming assimilations and majoring equilibrations, it is impossible not to recognize the outstanding position occupied by Ferreiro and Teberosky in the discourse order on literacy in our country.

Keywords: Psychogenesis. Written language. Literacy. Historiography.

\section{Referências}

FERREIRO, Emilia; TEBEROSKY, Ana. Psicogênese da lingua escrita. Porto Alegre: Artes Médicas, 1985.

FOUCAULT, Michel. Microfísíca do poder. (org. Roberto Machado). Rio de Janeiro: Graal, 1986.

FOUCAULT, Michel . A ordem do discurso: aula inaugural do Collège de France, pronunciada em 2 de dezembro de 1970. Campinas: Loyola, 1998.

KAVANAGH, J.; MATTINGLY, I. (Ed.). Language by ear and by eye. Londres; Cambridge: MIT Press, 1972.

LOURENCO FILHO, Manuel Bergstrom. Testes ABC para verificação da maturidade necessária à aprendizagem da leitura e da escrita. 9. ed., São Paulo: Comp. Melhoramentos, 1967.

MALUF, Maria Regina. (Org). Metalinguagem e aquisição da escrita: contribuições da pesquisa para a prática da alfabetização. São Paulo: Casa do Psicólogo, 2003.

MORTATTI, Maria do Rosário Longo. Os sentidos da alfabetização. São Paulo 1876 - 1994. São Paulo: Editora UNESP, 2000.

Recebido: 01/06/2012 | Aprovado: 4/11/2012

Paulo Gurgel: Professor do Programa de Pesquisa e Pós-Graduação em Educação da Universidade Federal da Bahia. Doutor em Educação pela Pontifícia Universidade Católica de São Paulo (2003). 